\title{
ENSINO-APRENDIZAGEM DE (NOÇÕES) MATEMÁTICA(S) NA EDUCAÇÃO INFANTIL: UM PANORAMA DE ESTUDOS RECENTES
}

\author{
MATHEMATICS TEACHING-LEARNING IN EARLY CHILDHOOD \\ EDUCATION: AN OVERVIEW OF RECENT STUDIES
}

\author{
Eduarda Furlani Kresh \\ Escola SESI Rio do Sul \\ eduardakresch@gmail.com \\ Morgana Scheller \\ Instituto Federal Catarinense - IFC - Campus Rio do Sul \\ morganascheller@yahoo.com.br
}

\section{Resumo}

O estudo busca compreender o que versam os estudos brasileiros recentes que tratam do ensinoaprendizagem de (noções) matemática(s) na Educação Infantil. Para isso realizou-se uma pesquisa com abordagem qualitativa utilizando os procedimentos do Mapeamento na Pesquisa Educacional de Biembengut (2008). Os dados foram constituídos por meio de levantamento das produções nacionais recentes relativas ao tema em repositórios de acesso livre. Para a análise considerou-se como categorias estabelecidas a priori: a) o contexto; b) os objetivos; c) os procedimentos de constituição e análise de dados; d) as noções matemáticas exploradas e teorias de base; e) alfabetização/noções matemática e processos pedagógicos; f) os principais resultados e contribuições. Os resultados ampliam as discussões realizadas na área e, a partir deles, compreendeu-se que os estudos brasileiros recentes têm foco na criança e no professor, enfatizam principalmente o ensino de geometria e aritmética, a partir de uma base sociointeracionista e construtivista. Por fim, a formação docente polivalente é bastante discutida quando se refere às áreas do conhecimento específico, necessitando ainda ampliar o número de pesquisas referentes a formação inicial e continuada da(o) pedagoga(o).

Palavras-chave: Mapeamento. Matemática na Educação Infantil. Noções matemáticas.

\begin{abstract}
Brazilian studies about teaching-learning of (notions) mathematics (s) in Early Childhood are about. For this, a research with a qualitative approach was carried out using the procedures of Mapping in Educational Research. The data were constituted by means of a survey of recent national productions related to the theme in open access repositories. For the analysis, the following categories were considered: a) the context; b) the objectives; c) the procedures for the constitution and analysis of data; d) the mathematical notions explored and basic theories; e) literacy / mathematical notions and pedagogical processes; $f$ ) the main results and contributions. The results expand the discussions held in the area and, from them, it was understood that recent Brazilian studies focus on the child and the teacher, mainly emphasize the teaching of geometry and arithmetic, from a socio-interactionist and constructivist basis. Finally, multipurpose teacher training is widely discussed when referring to specific areas of knowledge, requiring further research on the initial and continuing training of early childhood teachers.

Keywords: Mapping. Mathematics in Early Childhood Education. Mathematical notions.
\end{abstract}


Kresh, E. F.; Scheller, M.

\title{
INTRODUÇÃO
}

O ser humano utiliza diferentes tipos de linguagens que ao longo da história foram sendo modificadas, aperfeiçoadas ou até mesmo, extintas. A linguagem perde o sentido se não compartilhada e, também, não existe comunicação sem ao menos dois seres. Cada área do conhecimento possui uma linguagem própria com signos, termos e conceitos específicos. Como o contato com essas áreas ocorre por meio da língua materna, com a linguagem matemática não seria diferente pois ela é um conhecimento a ser compartilhado para sua perpetuação e evolução.

A matemática é uma linguagem composta de signos e de significados - como outras linguagens - um meio comunicação, de condução de informação, de construção e desconstrução de conceitos, ou seja, um código a ser utilizado na sociedade humana. Da mesma forma, Danyluk (2015, p. 25), define que,

\begin{abstract}
A matemática tem uma linguagem de abstração completa. Como qualquer sistema linguístico, a ciência matemática utiliza-se de signos para comunicar significados matemáticos. Assim, a leitura da linguagem matemática ocorre a partir da compreensão e da interpretação dos signos e das relações implícitas naquilo que é dito de matemática.
\end{abstract}

Atualmente, o principal meio de difusão desse conhecimento científico é a educação formal, em seus diferentes níveis e etapas, não que alguns aspectos não possam ser adquiridos de modo informal. A etapa responsável pela iniciação dessa linguagem na educação formal é a Educação Infantil (EI), enquanto a formalização e a sistematização desse conhecimento se dão nos Anos Iniciais do Ensino Fundamental.

No tocante a estudos que tratam de EI e (noções) matemática(s), Barbosa e Ferreira (2007) realizaram um levantamento bibliográfico das pesquisas realizadas no Brasil sobre a Psicologia e a Educação Matemática e perceberam que na época havia uma carência em pesquisas sobre esse tema na EI, sendo grande parte delas relacionadas ao Ensino Fundamental e Médio, ou ao conhecimento prévio adquirido antes do ingresso na educação formal. Isso pode ter ocorrido provavelmente devido a produção acadêmica a respeito do tema se dar em maior parte nos anos de 1980 e 1990, época em que a EI era ainda vista essencialmente como assistencialista. Além disso, as autoras perceberam que quando o foco é a cognição há uma diversidade de estudos, no entanto não foram encontrados “estudos sobre a construção do pensamento geométrico e construção da inteligência lógicomatemática" (BARBOSA; FERREIRA, 2007, p. 12). Outra lacuna mais recente percebida 
por Sanchez Junior, Blanco e Coelho Neto (2017), na revisão sistemática sobre matemática na EI, é que a maioria dos trabalhos se relacionam, principalmente, com a perspectiva do professor sobre o ensino-aprendizagem de matemática, ao invés de tratar desse processo em outras perspectivas. O mesmo estudo também identifica a necessidade do desenvolvimento de pesquisas de caráter prático, que apresentem propostas de estratégias/atividades para o ensino da Matemática na EI.

Tais estudos realizados e a identificação de lacunas existentes motivaram a realização desta investigação, que parte de questionamentos como: o que vem sendo investigado recentemente a respeito do desenvolvimento de (noções) matemática(s) na EI? Que indicativos as pesquisas fornecem a respeito de como trabalhar e garantir a formação dos conhecimentos matemáticos na primeira infância? O que os resultados, as lacunas e as perspectivas dos estudos podem contribuir para ampliação do conhecimento científico, voltado principalmente, para a exploração de noções matemáticas na EI?

Para tanto, considera-se que o desenvolvimento das noções matemáticas consiste em atividade imprescindível para o significado que a criança dará para a matemática e defende-se a necessidade, de como educador, que todos os envolvidos com educação da infância compreendam a aquisição da linguagem matemática. Assim, o presente estudo objetiva compreender o que versam os estudos brasileiros que tratam do ensinoaprendizagem de (noções) matemática(s) na EI. Para isso, tece-se inicialmente algumas considerações acerca de infância e educação seguido da apresentação dos procedimentos metodológicos e da discussão dos resultados do estudo em tela.

\section{DE INFÂNCIA E EDUCAÇÃO (MATEMÁTICA)}

O conceito de infância se transforma ao longo da história, já que em cada época existia um sentimento de infância. Até hoje é um conceito em construção, como bem expressa Kramer (1992, p. 12),

A idéia [sic] de infância, [...], não existiu sempre e nem da mesma maneira. Ao contrário, ela parece com a sociedade capitalista, urbano-industrial, na medida em que mudam a inserção e o papel social da criança na comunidade. Se na sociedade feudal a criança exercia um papel produtivo direto ("de adulto") assim que ultrapassava o período de alta mortalidade, na sociedade burguesa ela passa a ser alguém que precisa ser cuidada, escolarizada e preparada para uma atuação futura. Este conceito de infância é, pois, determinado historicamente pela modificação das formas de organização da sociedade. 
Portanto, a EI ficou instituída, a princípio, como assistencialista, e contemporaneamente com o objetivo de cuidar e educar (KRAMER, 2006) de modo indissociável e complementar (BRASIL, 2018). É a primeira etapa da Educação Básica, obrigatória a partir dos 4 anos, devendo ser oferecida pelo Estado em todo o território brasileiro. As Diretrizes Curriculares Nacionais para a Educação Infantil (DCNEI) já caracterizavam a EI como "[...] espaços institucionais não domésticos [...] regulados e supervisionados por órgão competente do sistema de ensino e submetidos a controle social" (BRASIL, 2010, p. 12). Atualmente, a Base Nacional Comum Curricular - BNCC (BRASIL, 2018) indica que nessa fase da criança as situações de aprendizagens devem considerar seus conhecimentos prévios, desenvolvendo-as por meio de interações e vivências. Portanto, o trabalho na EI deve articular "as experiências e os saberes das crianças com os conhecimentos que fazem parte do patrimônio cultural, artístico, ambiental, científico e tecnológico" (BRASIL, 2018, p. 41), proporcionando assim uma educação contextualizada e promotora de conhecimento ativo, a partir das experiências e dos saberes prévios.

Assim, pautado em interações e brincadeiras como eixos estruturantes (BRASIL, 2013), o educador pode contribuir para o desenvolvimento integral das crianças. Segundo a BNCC, a ação educativa pautada no cuidar e no educar assinala que esse último deve ser assegurado por seis direitos de aprendizagem e desenvolvimento (BRASIL, 2018) distribuídos ao longo de cinco campos de experiências. Isso porque a aprendizagem e o desenvolvimento integral não se tratam meramente de aprendizado espontâneo, portanto, necessita da intencionalidade educativa nas propostas pedagógicas que levem em consideração os tempos e espaços em que as crianças vivem e se movimentam.

Essa intencionalidade consiste na organização e proposição, pelo educador, de experiências que permitam às crianças conhecer a si e ao outro e de conhecer e compreender as relações com a natureza, com a cultura e com a produção científica, que se traduzem nas práticas de cuidados pessoais (alimentar-se, vestir-se, higienizar-se), nas brincadeiras, nas experimentações com materiais variados, na aproximação com a literatura e no encontro com as pessoas. (BRASIL, 2018, p. 37).

Ao estudar os campos de experiência que devem ser considerados na ação educativa do professor da EI percebe-se, de modo implícito, que vários objetivos podem ser relacionados às noções matemáticas, as quais serão consolidadas no Ensino Fundamental, principalmente aqueles contidos no campo de experiência denominado 'Espaços, tempos, 
quantidades, relações e transformações' (BRASIL, 2018) como pode-se visualizar no Mapa 1.

Mapa 1 - Objetivos de aprendizagem e desenvolvimento relativos ao campo de experiência "Espaços, tempos, quantidades, relações e transformações.

\begin{tabular}{|c|c|c|}
\hline $\begin{array}{l}\text { Bebês (zero a } 1 \text { ano e } 6 \\
\text { meses) }\end{array}$ & $\begin{array}{c}\text { Crianças bem pequenas ( } 1 \text { ano } \\
\text { e } 7 \text { meses a } 3 \text { anos e } 11 \text { meses }\end{array}$ & $\begin{array}{c}\text { Crianças pequenas (4 anos a } \\
5 \text { anos e } 11 \text { meses) }\end{array}$ \\
\hline $\begin{array}{l}\text { Explorar e descobrir as } \\
\text { propriedades de objetos e } \\
\text { materiais (odor, cor, sabor, } \\
\text { temperatura). }\end{array}$ & $\begin{array}{l}\text { Explorar e descrever } \\
\text { semelhanças e diferenças entre } \\
\text { as características e propriedades } \\
\text { dos objetos (textura, massa, } \\
\text { tamanho). }\end{array}$ & $\begin{array}{l}\text { Estabelecer relações de comparação } \\
\text { entre objetos, observando suas } \\
\text { propriedades. }\end{array}$ \\
\hline $\begin{array}{l}\text { Explorar relações de causa e } \\
\text { efeito (transbordar, tingir, } \\
\text { misturar, mover e remover } \\
\text { etc.) na interação com o } \\
\text { mundo físico. }\end{array}$ & $\begin{array}{l}\text { Observar, relatar e descrever } \\
\text { incidentes do cotidiano e } \\
\text { fenômenos naturais (luz solar, } \\
\text { vento, chuva etc.). }\end{array}$ & $\begin{array}{l}\text { Observar e descrever mudanças em } \\
\text { diferentes materiais, resultantes de } \\
\text { ações sobre eles, em experimentos e } \\
\text { envolvendo fenômenos naturais e } \\
\text { artificiais. }\end{array}$ \\
\hline $\begin{array}{l}\text { Explorar o ambiente pela ação } \\
\text { e observação, manipulando, } \\
\text { experimentando e fazendo } \\
\text { descobertas. }\end{array}$ & $\begin{array}{l}\text { Compartilhar, com outras } \\
\text { crianças, situações de cuidado } \\
\text { de plantas e animais nos espaços } \\
\text { da instituição e fora dela. }\end{array}$ & $\begin{array}{l}\text { Identificar e selecionar fontes de } \\
\text { informações, para responder a } \\
\text { questões sobre a natureza, seus } \\
\text { fenômenos, sua preservação. }\end{array}$ \\
\hline $\begin{array}{l}\text { Manipular, experimentar, } \\
\text { arrumar e explorar o espaço } \\
\text { por meio de experiências de } \\
\text { deslocamentos de si e dos } \\
\text { objetos. }\end{array}$ & $\begin{array}{l}\text { Identificar relações espaciais } \\
\text { (dentro e fora, em cima, } \\
\text { embaixo, acima, abaixo, entre e } \\
\text { do lado) e temporais (antes, } \\
\text { durante e depois). }\end{array}$ & $\begin{array}{l}\text { Registrar observações, } \\
\text { manipulações e medidas, usando } \\
\text { múltiplas linguagens (desenho, } \\
\text { registro, por números ou escrita } \\
\text { espontânea). }\end{array}$ \\
\hline $\begin{array}{l}\text { Manipular materiais diversos e } \\
\text { variados para comparar as } \\
\text { diferenças e semelhanças entre } \\
\text { eles. }\end{array}$ & $\begin{array}{l}\text { Classificar objetos, } \\
\text { considerando determinado } \\
\text { atributo (tamanho, peso, cor, } \\
\text { forma e etc). }\end{array}$ & $\begin{array}{l}\text { Classificar objetos e figuras, de } \\
\text { acordo com suas semelhanças e } \\
\text { diferenças }\end{array}$ \\
\hline $\begin{array}{l}\text { Experimentar e resolver } \\
\text { situações-problema do seu } \\
\text { cotidiano. }\end{array}$ & $\begin{array}{l}\text { Analisar situações-problema do } \\
\text { cotidiano, levantando hipóteses, } \\
\text { dados e possibilidades de } \\
\text { solução. }\end{array}$ & $\begin{array}{l}\text { Resolver situações-problema, } \\
\text { formulando questões, levantando } \\
\text { hipóteses, organizando dados, } \\
\text { testando possibilidades de solução. }\end{array}$ \\
\hline \multirow[t]{3}{*}{$\begin{array}{l}\text { Vivenciar diferentes ritmos, } \\
\text { velocidade e fluxos nas } \\
\text { interações e brincadeiras (em } \\
\text { danças, balanços, } \\
\text { escorregadores, etc). }\end{array}$} & $\begin{array}{l}\text { Utilizar conceitos básicos de } \\
\text { tempo (agora, antes, durante, } \\
\text { depois, ontem, hoje, amanhã, } \\
\text { lento, rápido, depressa, } \\
\text { devagar). }\end{array}$ & $\begin{array}{l}\text { Relatar fatos importantes sobre seu } \\
\text { nascimento e desenvolvimento, a } \\
\text { história dos seus familiares e da sua } \\
\text { comunidade. }\end{array}$ \\
\hline & $\begin{array}{l}\text { Contar oralmente objetos, } \\
\text { pessoas, livros etc., em } \\
\text { contextos diversos. }\end{array}$ & $\begin{array}{l}\text { Relacionar números às suas } \\
\text { respectivas quantidades e } \\
\text { identificar o antes, o depois e o } \\
\text { entre em uma sequência. }\end{array}$ \\
\hline & $\begin{array}{l}\text { Registrar com números a } \\
\text { quantidade de crianças. }\end{array}$ & $\begin{array}{l}\text { Expressar medidas (peso, altura, } \\
\text { etc.), construindo gráficos básicos. }\end{array}$ \\
\hline
\end{tabular}

Fonte: Brasil (2018, p. 50).

Pode-se perceber que tais objetivos irão contribuir para que as crianças desenvolvam na EI aprendizagens relativas às noções de localização e orientação, de grandezas e medidas, de geometria e de elementos essenciais para construção da noção de número que devem ser consolidadas nos Anos Iniciais. Assim, tais noções contribuem para 
a alfabetização matemática dessas crianças. De vários dos estudos já realizados a respeito de alfabetização matemática, a maioria deles acabam por ignorar a contribuição do ensino de noções na EI e dos próprios conhecimentos prévios das crianças (DANYLUK, 2015). É necessário desenvolver o conhecimento matemático já na primeira etapa da Educação Básica, mas não de modo conteudista e sim por meio das experiências, interações e brincadeiras. Sendo assim, a EI não é o lugar a ser iniciada a alfabetização matemática propriamente dita, mas sim um espaço onde as crianças podem se aproximar e desenvolver as primeiras noções matemáticas (DANYLUK, 1989).

Para instigar essas relações, o lúdico é o principal mediador, pois "ao brincar ou jogar, a criança potencializa sua possibilidade de aprender e de se apropriar de novos conhecimentos" (MORETTI; SOUZA, 2015, p. 31). A importância do brincar também é enfatizada por Smole, Diniz e Cândido (2000), ao acreditarem que a troca de informação e a interação social que proporciona a brincadeira é fundamental para reflexão, investigação e solução de situações-problemas.

De modo geral, o brincar oferece à criança situações em que as habilidades físicas e mentais podem ser praticadas por diversas vezes, além de poder explorar os potenciais e limitações da criança. Junto com o brincar, é preciso salientar que está relacionado a este ato os materiais oferecidos à criança para cada situação. (SILVA, 2013).

Portanto, a inserção das crianças aos conhecimentos matemáticos deve se dar por meio lúdico e na relação corpo, meio e objeto. É por meio dessas interações e reflexões que o conhecimento matemático se constrói na primeira infância e se consolida na segunda etapa da Educação Básica, pois, como bem indica a BNCC, os Anos Iniciais do Ensino Fundamental, necessitam articular "com as experiências vivenciadas na Educação Infantil" (BRASIL, 2018, p. 55), partindo das experiências lúdicas de aprendizagem, porém, prevendo uma progressiva sistematização. Assim, nessa segunda etapa "deve-se retomar as vivências cotidianas das crianças com números, formas e espaço, e as experiências desenvolvidas na EI, para iniciar uma sistematização dessas noções" (BRASIL, 2018, p. 276). E é compreendendo a importância do desenvolvimento de noções durante a EI, que entenderemos e teremos condições de propiciar futura sistematização e a consolidação desse conhecimento nos Anos Iniciais. 
Kresh, E. F.; Scheller, M.

\title{
ASPECTOS METODOLÓGICOS
}

Este estudo apresenta característica de abordagem qualitativa de pesquisa em educação (BOGDAN; BIKLEN, 1994) e utilizou os princípios do Mapeamento na Pesquisa Educacional de Biembengut (2008). O Mapeamento consiste em uma série de procedimentos que envolvem desde a identificação do tema/assunto, da situação-problema até a análise dos elementos envolvidos, a saber:

\begin{abstract}
identificação dos entes ou dados envolvidos com o problema a ser pesquisado, para, a seguir, levantar, classificar e organizar tais dados de forma a tornarem mais aparentes as questões a serem avaliadas; reconhecer padrões, evidências, traços comuns ou peculiares, ou ainda características indicadoras de relações genéricas, tendo como referência o espaço geográfico, o tempo, a história, a cultura, os valores, as crenças e as ideias dos entes envolvidos - a análise. (BIEMBENGUT, 2008, p. 74).
\end{abstract}

O Mapeamento a ser elaborado consiste, basicamente, na revisão da literatura sobre os conceitos e pesquisas desenvolvidas recentemente, para assim dominar o conhecimento já produzido na área investigada, bem como "conhecer as questões que envolvem as ações educacionais ou pedagógicas" (BIEMBENGUT, 2008, p. 90), com o propósito de compreender, analisar e representar os dados ou informações coletadas. A partir do aspecto 'produções recentes' indicada para o Mapeamento, este estudo considera as produções relativas ao período de 2008 a 2019.

Assim, para a constituição do corpus de análise iniciou-se o estudo com busca em repositórios ou bancos de dados virtuais de acesso livre como: (i) Portal de Periódicos da Coordenação de Aperfeiçoamento de Pessoal de Nível Superior (CAPES); (ii) Portal SciELO (Scientific Electronic Library Online); (iii) Biblioteca Digital de Teses e Dissertações (BDTD); (iv) anais de reuniões da Associação Nacional de Pós-Graduação e Pesquisa em Educação (ANPEd); (v) Google acadêmico; e (vi) artigos publicados em revistas qualificadas. Foram selecionadas as produções recentes divulgadas na forma de teses, dissertações e artigos publicados em revistas científicas (Qualis A1-B2) que apresentam relação com a problemática proposta, sendo os mesmos encontrados por meio da combinação de duas das palavras-chave: "Educação Infantil” + "matemática"; ou + “desenvolvimento cognitivo". Posteriormente, procedeu-se com a leitura do resumo dos textos excluindo os que não eram relacionados com o tema. Dos selecionados, ainda foi realizada uma leitura flutuante para agrupar as pesquisas que realmente contribuam com a problemática exposta. O Mapa 2 expressa o quantitativo obtido nessa busca. 
Kresh, E. F.; Scheller, M.

Mapa 2 - Quantitativo de estudos na forma de artigos para composição do corpus de análise.

\begin{tabular}{cccc}
\hline Banco de dados & Estudos encontrados & Estudos pré-selecionados & Corpus de análise \\
\hline Google Acadêmico & 200 & 4 & 3 \\
Periódicos da CAPES & 560 & 32 & 15 \\
SciELO & 30 & 8 & 4 \\
BDTD & 202 & 9 & 9 \\
ANPEd & 2 & 1 & 1 \\
Revistas & 197 & 28 & 19 \\
\hline TOTAL & $\mathbf{1 1 9 1}$ & $\mathbf{6 7}$ & $\mathbf{5 2}$ \\
\hline
\end{tabular}

Fonte: Elaborado pelos autores.

Na sequência, os estudos componentes do corpus de análise foram identificados por um código alfanumérico de acordo com a forma que foram apresentados e encontrados durante a busca: (i) AR para artigos de revistos; (ii) DI para dissertação; e (iii) TE para teses. Destaca-se que no caso dos artigos publicados e que se constituíam de recortes de teses (TE), optou pela análise da produção original.

Desse modo, após a seleção e organização dos estudos, foram estabelecidos critérios para análise - as categorias -, dentre eles: a) contexto das pesquisas; b) objetivo; c) procedimentos de pesquisa; d) noção matemática exploradas e teorias de base; e) Alfabetização/noções matemática e processos pedagógicos; f) principais resultados e contribuições. Eles são apresentados e discutidos no tópico a seguir.

\section{RESULTADOS E DISCUSSÕES}

Os 52 estudos selecionados nos bancos de dados, constituintes do corpus de análise após leitura atenta, encontram-se registradas no Mapa 3.

Mapa 3 - Estudos na forma de Teses, Dissertações e Artigos que compõe o corpus de análise.

\begin{tabular}{|c|l|c|}
\hline Identificação & \multicolumn{1}{|c|}{ Título } & Ano \\
\hline AR1 & $\begin{array}{l}\text { A Matemática em uma turma de Educação Infantil: algumas situações do } \\
\text { cotidiano }\end{array}$ & 2019 \\
\hline AR2 & $\begin{array}{l}\text { Protagonismo infantil e saberes culturais ribeirinhos no ensino de matemática } \\
\text { na Educação Infantil }\end{array}$ & 2018 \\
\hline AR3 & $\begin{array}{l}\text { Estudo sobre a prática de alfabetização matemática de professoras da Educação } \\
\text { Infantil }\end{array}$ & 2015 \\
\hline AR4 & $\begin{array}{l}\text { Os caminhos escolhidos pela Educação Infantil para alfabetizar } \\
\text { matematicamente as crianças de 04 e 05 anos }\end{array}$ & 2016 \\
\hline AR5 & Que matemática é preciso saber para ensinar na Educação Infantil? & 2012 \\
\hline AR6 & $\begin{array}{l}\text { O ensino de matemática na Educação Infantil: uma proposta de trabalho com } \\
\text { jogos }\end{array}$ & 2017 \\
\hline AR7 & $\begin{array}{l}\text { "É perto, mas é muito, muito longe": conversando com crianças sobre senso } \\
\text { espacial }\end{array}$ & 2019 \\
\hline AR8 & $\begin{array}{l}\text { O desenvolvimento da Cognição Numérica: compreensão necessária para o } \\
\text { professor que ensina Matemática na Educação Infantil }\end{array}$ & 2018 \\
\hline AR9 & $\begin{array}{l}\text { "Ou isto ou aquilo": comparativo entre a Matemática da Educação Infantil nas } \\
\text { Diretrizes e na Base Nacional Comum Curricular }\end{array}$ & 2018 \\
\hline
\end{tabular}




\begin{tabular}{|c|c|c|}
\hline AR10 & Classificação na Educação Infantil: discutindo propostas, concepções e práticas & 2017 \\
\hline AR11 & A construção das noções de espaço e tempo nas crianças da Educação Infantil & 2010 \\
\hline AR12 & $\begin{array}{l}\text { Conhecimento especializado revelado por professores da Educação Infantil e dos } \\
\text { anos iniciais no tema de medida de comprimento e sua estimativa }\end{array}$ & 2017 \\
\hline AR13 & $\begin{array}{l}\text { Ensinando matemática aos bebês encantos, descobertas e exploração das } \\
\text { relações entre grandezas }\end{array}$ & 2017 \\
\hline AR14 & Desenvolvimento do conceito de espaço em crianças e a Educação Infantil & 2009 \\
\hline AR15 & $\begin{array}{l}\text { Tarefas matemáticas para o desenvolvimento da percepção de espaço na } \\
\text { Educação Infantil: potencialidades e limites }\end{array}$ & 2018 \\
\hline AR16 & $\begin{array}{l}\text { Das competências quantitativas iniciais para o conceito de número natural: } \\
\text { quais as trilhas possíveis? }\end{array}$ & 2012 \\
\hline AR17 & $\begin{array}{l}\text { Aprendizagens de professoras da Educação Infantil: a geometria a partir da } \\
\text { exploração-investigação matemática }\end{array}$ & 2008 \\
\hline AR18 & Geometria e Educação Infantil: um estudo de inspiração etnomatemática & 2019 \\
\hline AR19 & $\begin{array}{l}\text { Geometria na Educação Infantil: da manipulação empirista ao concreto } \\
\text { piagetiano }\end{array}$ & 2012 \\
\hline AR20 & $\begin{array}{l}\text { Formação de professores/educadores para o ensino e a aprendizagem das } \\
\text { capacidades espaciais na Educação Infantil }\end{array}$ & 2019 \\
\hline AR21 & A matemática das crianças pequenas e a literatura infantil & 2005 \\
\hline AR22 & $\begin{array}{l}\text { Educação Infantil na trilha das múltiplas inteligências: uma proposta de } \\
\text { construção do conhecimento a partir de salas ambiente }\end{array}$ & 2015 \\
\hline AR23 & Entre caixas, bolas e bambolês: a orientação espacial na Educação Infantil & 2017 \\
\hline AR24 & $\begin{array}{l}\text { Qual matemática para crianças tão pequenas? Explorando as noções de espaço } \\
\text { com crianças de } 1 \text { a } 3 \text { anos }\end{array}$ & 2013 \\
\hline AR25 & $\begin{array}{l}\text { Reflexão sobre a prática da contagem: diálogo entre educador infantil, } \\
\text { pesquisador e criança }\end{array}$ & 2009 \\
\hline AR26 & $\begin{array}{l}\text { Uma proposta de integração entre a matemática e a literatura infantil em } \\
\text { contexto de jardim de infância }\end{array}$ & 2011 \\
\hline AR27 & $\begin{array}{l}\text { A modelagem computacional na Educação Infantil: teorização e possibilidade } \\
\text { de implementação pedagógica }\end{array}$ & 2016 \\
\hline AR28 & $\begin{array}{l}\text { Mateludicando na Educação Infantil: um modelo de prática pedagógica para } \\
\text { crianças pequenas }\end{array}$ & 2015 \\
\hline AR29 & Uma revisão sistemática sobre o ensino da matemática na Educação Infantil & 2017 \\
\hline AR30 & $\begin{array}{l}\text { Jogos e brincadeiras propiciando o desenvolvimento de noções matemáticas na } \\
\text { Educação Infantil }\end{array}$ & 2018 \\
\hline AR31 & $\begin{array}{l}\text { Resolução de problemas na Educação Infantil: uma análise do uso da estrutura } \\
\text { multiplicativa }\end{array}$ & 2015 \\
\hline AR32 & A Educação estatística na Educação Infantil e nos Anos Iniciais & 2009 \\
\hline AR33 & $\begin{array}{l}\text { Matemática e Infância no "Referencial Curricular Nacional para a Educação } \\
\text { Infantil": um olhar a partir da teoria histórico-cultural }\end{array}$ & 2010 \\
\hline AR34 & Estratégias utilizadas por crianças da Educação Infantil para classificar & 2016 \\
\hline AR35 & Contar nos dedos: a conceitualização de número e operação de adição & 2017 \\
\hline AR36 & Infância e matemática: aprendendo sobre medidas de comprimento & 2016 \\
\hline AR37 & $\begin{array}{l}\text { O que tem dentro? O que mudou? Desenho de tarefas para promover percepções } \\
\text { matemáticas na Educação Infantil }\end{array}$ & 2016 \\
\hline AR38 & Contagem e construção do número por crianças da Educação Infantil & 2016 \\
\hline AR39 & $\begin{array}{l}\text { Pra lá e pra cá, vou a qualquer lugar! O papel do corpo e do seu movimento no } \\
\text { contexto das tarefas para o desenvolvimento da percepção espacial na Educação } \\
\text { Infantil }\end{array}$ & 2018 \\
\hline DI1 & $\begin{array}{l}\text { A resolução de problemas de estrutura aditiva por crianças da Educação } \\
\text { Infantil: o uso de jogos e problemas escolares }\end{array}$ & 2009 \\
\hline DI2 & $\begin{array}{l}\text { A literatura infantil e a matemática: um estudo com alunos de } 5 \text { e } 6 \text { anos de } \\
\text { idade da Educação Infantil }\end{array}$ & 2010 \\
\hline DI3 & Modelagem matemática na Educação Infantil: uma estratégia de ensino com & 2013 \\
\hline
\end{tabular}


Kresh, E. F.; Scheller, M.

\begin{tabular}{|c|l|c|}
\hline & crianças da faixa etária de 4 a 5 anos & 2015 \\
\hline DI4 & $\begin{array}{l}\text { Criança, infância e conhecimento matemático: um estudo a partir da teoria } \\
\text { historico-cultural }\end{array}$ & 2015 \\
\hline DI5 & A orientação espacial na pré-escola: analisando saberes docentes & 2015 \\
\hline DI6 & Trabalhando com unidades de medida e estimativas na Educação Infantil & 2015 \\
\hline DI7 & $\begin{array}{l}\text { Problematizações a partir de situações emergentes do cotidiano: compreensões } \\
\text { e possibilidades envolvendo relações quantitativas, medidas, formas e e } \\
\text { orientações de espaço temporais em turmas de crianças de quatro anos }\end{array}$ & 2017 \\
\hline DI8 & O brincar e as concepções de conceitos matemáticos de crianças de 5 anos & 2018 \\
\hline DI9 & $\begin{array}{l}\text { Ensino da matemática na Educação Infantil: uma análise das percepções de } \\
\text { professores e dos jogos de linguagem presentes em sua prática docente }\end{array}$ & 2016 \\
\hline DI10 & $\begin{array}{l}\text { A criança da Educação Infantil e a linguagem matemática: relações } \\
\text { interdependentes no processo de ensino e aprendizagem }\end{array}$ & 2012 \\
\hline TE1 & $\begin{array}{l}\text { O conhecimento matemático na Educação Infantil: o movimento de um grupo } \\
\text { de professoras em processo de formação continuada }\end{array}$ & 2003 \\
\hline TE2 & $\begin{array}{l}\text { O conhecimento profissional dos professores e suas relações com estatística e } \\
\text { probabilidade na Educação Infantil }\end{array}$ & 2010 \\
\hline TE3 & $\begin{array}{l}\text { Um estudo dos conceitos numéricos iniciais em crianças inseridas no ambiente } \\
\text { escolar de Educação Infantil }\end{array}$ & 2 \\
\hline
\end{tabular}

Fonte: Elaborado pelos autores.

Inicialmente, a partir do corpus, apresenta-se a distribuição temporal dos estudos, ao objeto de estudo e ao contexto, com o intuito ilustrar quando, onde e em que circunstâncias foram desenvolvidos e publicados, bem como os motivos da realização deles e demais informações sobre o campo de pesquisa. Desse modo, o Mapa 4 apresenta um panorama temporal da publicação dessas pesquisas.

Mapa 4 - Distribuição dos estudos de acordo com o período de publicação.

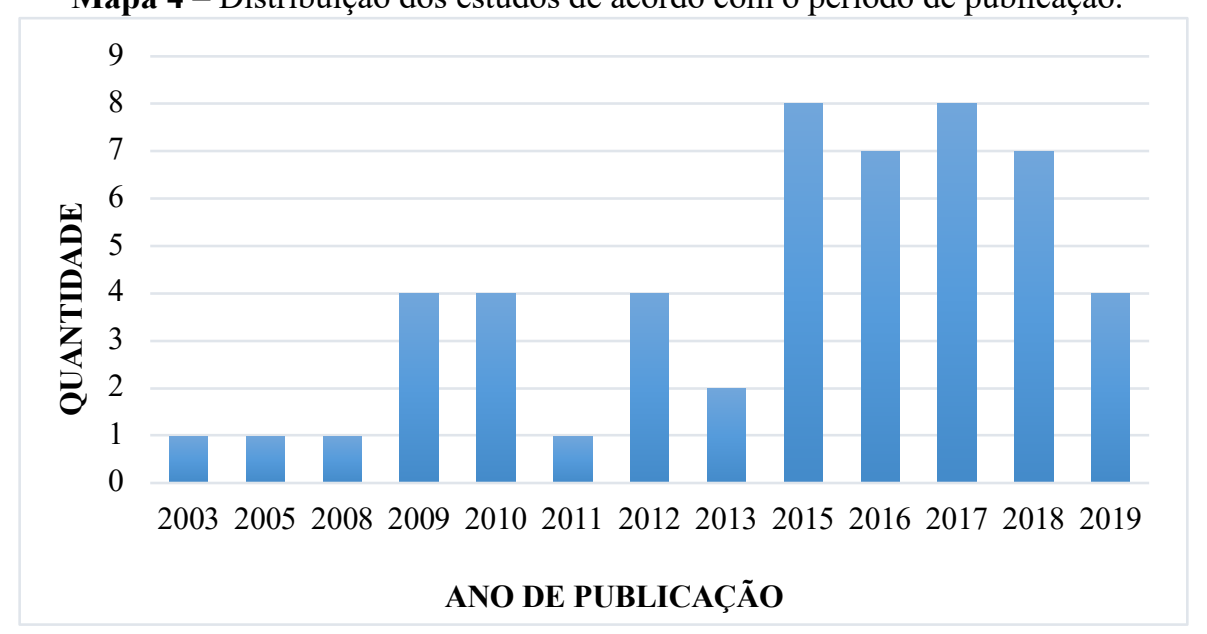

Fonte: Elaborado pelos autores.

\footnotetext{
${ }^{1}$ Tese considerada nesse estudo uma vez que se identificou na busca o artigo 'Narrativas de práticas pedagógicas de professoras que ensinam matemática na educação infantil', recorte da tese.

${ }^{2}$ Tese considerada nesse estudo uma vez que se identificou na busca o artigo 'Combinando roupas e vestindo bonecos: ideias de combinatória no desenvolvimento profissional de uma educadora da infância', recorte da tese.

${ }^{3}$ Tese considerada nesse estudo uma vez que se identificou na busca o artigo 'Conceitos numéricos na educação infantil: uma pesquisa etnográfica, recorte da tese.
} 
Nota-se que a maior concentração dos estudos publicados está localizada no período de 2015 a 2018 (57,7\%), com maior pico em 2015 após não ser identificada nenhuma produção em 2014 relativa ao tema, fato bastante questionador. O aumento no número de publicações nesse período, provavelmente, deve-se ao aumento do número de Programas de Pós-graduação na Educação brasileira e também, pelo incentivo à formação stricto sensu realizado por meio de bolsas de estudos aos (futuros) pesquisadores. Também deve-se considerar que foi a partir dos anos 2000 que os periódicos passam a publicar no formato online o que até então ocorria, na maior parte, de modo impresso. Isso também pode ter inferido nesse quantitativo, principalmente na primeira década do século.

Destaca-se que dois estudos se encontram num período anterior a 2008: A21 e TE3. O primeiro foi selecionado devido a relevância para o tema, enquanto que o segundo referese a base de um artigo identificado na busca dentro o período.

Referente ao objeto de pesquisa, dos 39 artigos, 36\% tiveram foco na criança, 20\% no professor da EI, ao passo que os estudos bibliográficos e/ou documentais totalizam $26 \%$. Das 10 dissertações, $20 \%$ delas tiveram foco no professor, enquanto que das teses, $66 \%$ escolheram o professor como foco de estudo. Destaca-se que a minoria dos estudos utiliza os documentos oficiais como ponto central da pesquisa (D4, AR9 e AR33), ao passo que os estudos em torno da profissão docente se destacam. Assim, tal como a pesquisa de Sanchez Junior, Blanco e Coelho Neto (2017), a presente pesquisa também constatou que o objeto de pesquisa está mais voltado para como se dá o ensino do que para o processo de aprendizagem das crianças. Na maior parte delas, o foco das noções matemática na infância reside principalmente na formação de professores, por meio de discussões teóricas ou da percepção desses professores acerca do ensino e aprendizagem da Matemática.

Em relação ao contexto dos estudos, 94\% deles referem-se exclusivamente à EI e $6 \%$ consideram tanto o contexto da EI, quanto dos Anos Iniciais. Ressalta-se que das teses e dissertações, todas foram desenvolvidas no cenário da EI, sendo cinco voltados para a observação da ação do professor. Das pesquisas empíricas (39) - que explicitavam o campo e os sujeitos da coleta de dados - pode-se perceber que $90 \%$ delas foram desenvolvidas em instituições públicas sendo apenas quatro, o campo empírico foram escolas particulares. Já em relação às teses e dissertações, 69\% provêm de universidades públicas. Sendo assim, os campos de coleta de dados, em sua maioria, são da rede pública e os trabalhos 
acadêmicos - teses e dissertações - são em sua maioria oriundos de programas de pósgraduação de instituições públicas.

Esse fator nos permite compreender que a educação pública pode estar mais próxima, preocupada e comprometida com a construção do conhecimento científico. No que se refere ao campo de coleta de dados, o percentual pode ter se dado pela facilidade de acesso ou por abranger uma maior população e com caráter social mais relevante para as pesquisas. Já a produção científica das universidades públicas é visivelmente maior, o que resulta, provavelmente, de um maior incentivo às pesquisas, constituindo efetivamente a formação baseada no tripé ensino-pesquisa-extensão. As concentrações regionais das universidades e sua produção científica pode também ser um fator determinante quanto a distribuição geográfica das pesquisas, conforme percebe-se no Mapa 5.

A partir da visualização do Mapa 5 percebe-se que no Brasil há uma irregular distribuição geográfica dos estudos. É evidente uma regionalização, uma vez que a maioria das pesquisas publicadas são originárias de pesquisadores e instituições localizadas no Sul do Brasil (46\%), seguido do Sudeste com 23\% do total. Já as demais regiões têm um número menos significativo, sendo $17 \%$ do Nordeste, $8 \%$ do Centro-Oeste e $4 \%$ do Norte. Além disso, o Paraná destaca-se com a maior quantidade de publicações (21\%). Tais resultados indicam que a região $\mathrm{Sul}$, apesar de ter menor número de grupos de pesquisas ${ }^{4}$ que a Sudeste, quando o assunto é a matemática na EI, a mesma lidera as produções recentes com $46 \%$ do total, o dobro das produções registradas na região Sudeste.

\footnotetext{
${ }^{4}$ Censo de 2016, disponível em http://lattes.cnpq.br/web/dgp/censo-atual/. O Censo constatou que os grupos de pesquisa registrados estão assim distribuídos: Norte: 6,3\%, Centro-oeste: 7,7\%, Nordeste: 20,5\%, Sul: 22,9\% e Sudeste: 42,5\%. O crescimento percentual do número de grupos cadastrados 2016 em relação a 2014 por unidade da federação foi: Norte: 15\%, Nordeste: 7\%, Centro-oeste: 9\%, Sul: 9\% e Sudeste: 3\%.
} 
Kresh, E. F.; Scheller, M.

Mapa 5 - Estudos do corpus de análise distribuído conforme o estado brasileiro de origem da publicação.

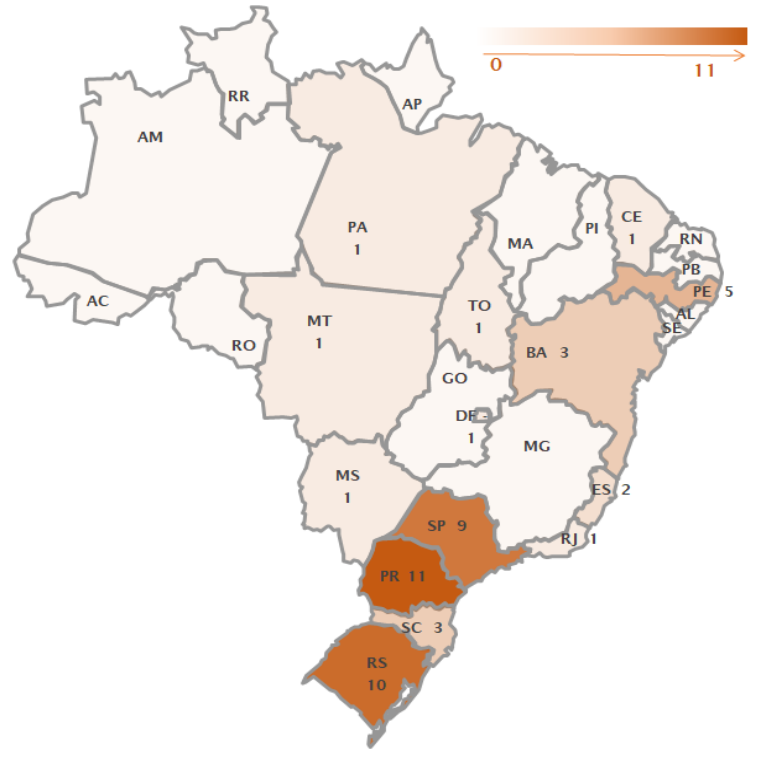

Fonte: Elaborado pelos autores.

Em relação às noções matemáticas abordadas nos estudos, os mesmos forneceram dados relevantes para pesquisa na educação matemática, principalmente relacionado a má distribuição no que se refere aos campos da matemática. A aritmética (11 estudos) e a geometria (15 estudos) se destacam pela sua presença em $70 \%$ das pesquisas que fazem referência a alguma noção matemática. Cavalcante (2015) apontou em seu estudo que o enfoque maior das pesquisas realizadas estava voltado para aritmética, reconhecendo que a geometria vinha se destacando. Nossos resultados já indicam essa superação. No entanto o fato dos demais campos serem ainda pouco explorados em pesquisas ainda permanece, tal como destacado pelo autor. No Mapa 6 apresenta-se um panorama da distribuição quando relações aos campos da matemática.

Mapa 6 - Relação proporcional entre as noções matemáticas abordadas nos estudos.

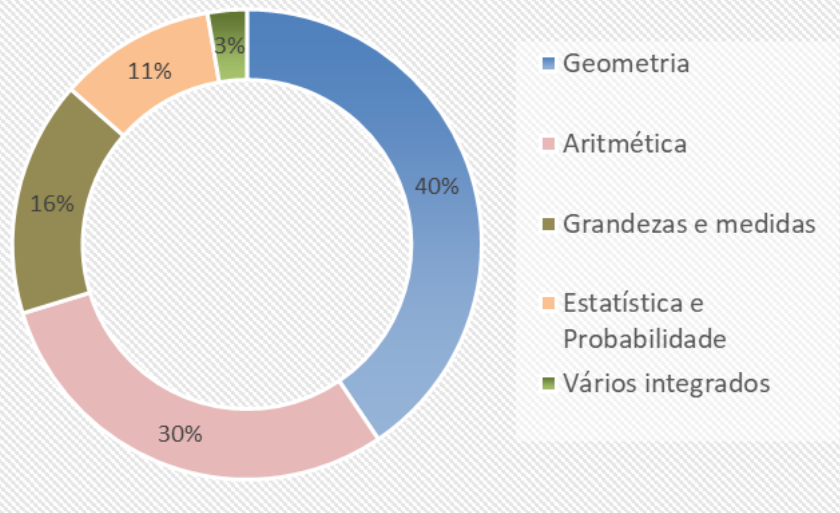

Fonte: Elaborado pelos autores. 
Kresh, E. F.; Scheller, M.

De acordo com o Mapa 6, tem-se mais evidente a dissonância entre as noções matemáticas que são discutidas ou foco nos estudos: um maior bloco inclui a aritmética e geometria, enquanto que um número significativamente reduzido direcionou foco para o campo das grandezas e medidas e, estatística e probabilidade. Por fim, destaca-se que a álgebra não foi evidenciada como foco nos estudos e isso pode estar relacionado à pouca ênfase que os documentos oficiais davam a ela antes da BNCC.

O documento normativo mais recente, a BNCC, contempla as noções matemáticas principalmente no campo de experiência denominado "Espaços, tempos, quantidades, relações e transformações", evidenciando que deve ser desenvolvida na EI noções de tempo, espaço, localização (geometria); contagem, ordenação, relação de quantidade, números cardinais e ordinais (aritmética); dimensões, medidas, pesos, comprimentos (grandezas e medidas); classificação (álgebra); gráficos básicos (estatística e probabilidade) (BRASIL, 2018). Apesar de não separar em campos específicos da matemática é perceptível que todas as unidades temáticas presentes já estão sendo contempladas nas orientações referentes à EI.

Os resultados indicam, para além da ênfase nas noções numéricas evidenciadas por Cavalcante (2015), que há agora ênfase maior na geometria, evidenciando que a lacuna apontada por Barbosa e Ferreira (2007) da carência de estudos em pensamento geométrico pode não mais existir. Tais estudos se dedicam a investigar aspectos relacionados à: localização e orientação (AR7, AR23, AR39 e DI5); percepção espacial (AR 15 e AR37); problemas e capacidades espaciais (AR24 e A20); noção e conceito de espaço (AR11, AR14 e AR18) ou avaliar conhecimentos de geometria (AR17 e AR19). Já as que contemplam tópicos de aritméticas, destinam-se a estudos sobre a construção da noção de número (AR3, AR4 e AR16) ou de contagem (AR25, AR35 e DI1) e estruturas aditivas e/ou multiplicativas (DI3 e AR31).

Entendendo que o ensino de matemática na EI deveria contemplar todos as temáticas da matemática implícitos nos campos de experiência, esperava-se ao iniciar este estudo que as pesquisas científicas também atendessem também todas as noções matemáticas. A divergência da BNCC e de outros documentos da educação, com a produção científica, referente aos conceitos da matemática a serem trabalhados, leva a questionar o porquê de serem priorizados alguns conteúdos em detrimento aos outros. Um 
exemplo seria a lacuna relativa a estudos que culminam nas noções de probabilidade e estatística, ou até mesmo à álgebra, cujas noções já podem ser explorados desde a EI.

Outro aspecto também analisado nos estudos foi seu objetivo principal de cada um deles, ou seja, a pretensão principal de cada pesquisa. Segundo Gil (2009, p. 162), para sua indicação desse recomenda-se a utilização de "verbos de ação, como identificar, verificar, descrever e analisar" quando deseja-se expor o objetivo da pesquisa, tal como foi observado no corpus. Dentre todos objetivos identificados nos 52 estudos, o verbo 'investigar' foi o mais utilizado, seguido do verbo 'analisar'. Com menor ocorrência registrou-se o 'discutir', o 'apresentar', o 'compreender', o 'identificar', o 'verificar', o 'refletir', o 'examinar', o 'descrever', o 'mostrar', o 'relatar', o 'comparar', o 'estudar' e o 'reconhecer'.

Em busca de maior compreensão desses objetivos, realizou-se uma classificação inspirada na Taxonomia de Bloom ${ }^{5}$ que evidenciou três diferentes grupos. O primeiro grupo é o do conhecimento que abrange verbos como reconhecer, apresentar, descrever, relatar ou identificar, ou seja, são utilizados pelos autores quando procuram reconhecer e revisitar dados. O segundo grupo, denominado de compreensão, inclui objetivos que buscam traduzir o conteúdo compreendido entendendo-o e dando significado a ele, representado nesse caso pelos verbos discutir ou compreender, por exemplo. O último grupo é o da análise, com os verbos como investigar, analisar, examinar, que fazem referência ao aprofundamento do problema de pesquisa, dissecando e examinando os resultados. O Mapa 7 ilustra o resultado dessa classificação.

\footnotetext{
${ }^{5}$ Taxonomia vem do grego taxis - ordem - e nomos - sistema. Ou seja, um sistema de classificação criada por estudiosos liderados por Benjamin S. Bloom em 1956, porém "não é apenas um esquema para classificação, mas uma possibilidade de organização hierárquica dos processos cognitivos de acordo com níveis de complexidade e objetivos do desenvolvimento cognitivo". As categorias do domínio cognitivo, da mais simples à mais complexa, são: conhecimento, compreensão, aplicação, análise, síntese e avaliação (FERRAZ; BELHOT, 2010).
} 
Kresh, E. F.; Scheller, M.

Mapa 7 - Classificação dos objetivos em três grandes grupos, baseado na Taxonomia de Bloom.

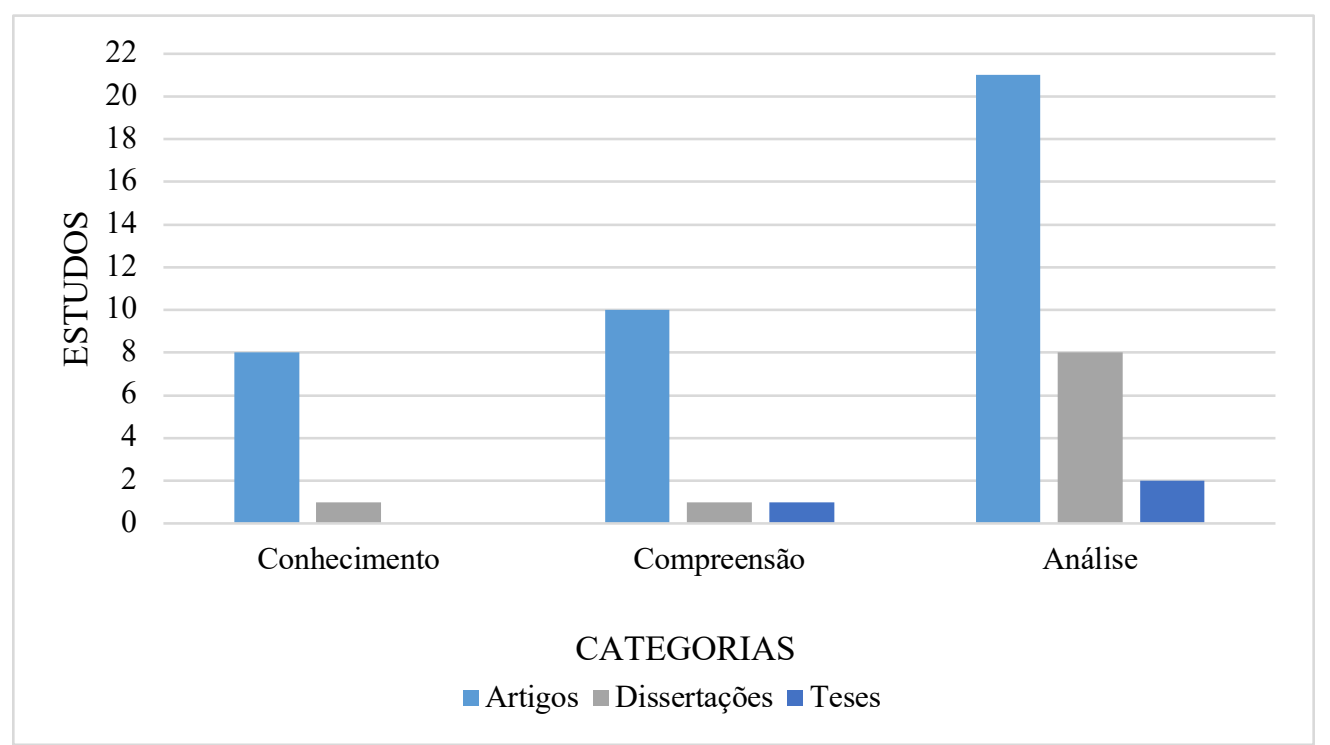

Fonte: Elaborado pelos autores.

A partir do Mapa 7, percebe-se que a concentração maior dos estudos apresentam objetivos classificados como de análise $(59,6 \%)$, que visam identificar as partes e suas inter-relações, principalmente com o intuito de investigar ou analisar a situação proposta. Esses objetivos de análise foram identificados em $66 \%$ das teses, $80 \%$ das dissertações e $54 \%$ dos artigos. Já os de compreensão $(23,1 \%)$ estiveram mais relacionados à releitura de informação e foram identificados em $29 \%$ dos artigos. Por fim, os de conhecimento que visam significar as informações, representam 17,3\% do total. Destaca-se que essas últimas duas categorias estão mais relacionadas a releitura das informações, enquanto que na primeira categoria, a significá-las. Assim, percebe-se que os objetivos desses estudos buscam investigar ou analisar um fenômeno, objetivos caracterizados por elevados níveis de complexidade de acordo com a taxonomia de Bloom, pois envolvem além da compreensão o domínio da estrutura do objeto analisado. Ademais, identificou-se que a minoria dos estudos que pretendeu apenas realizar discussão teórica ou revisão de literatura.

Em relação aos procedimentos de pesquisa, destaca-se que as teses e dissertações utilizam principalmente da combinação da pesquisa empírica com aporte teórico para discussão dos resultados, enquanto que os artigos se dividem entre esse modo e a pesquisa bibliográfica ou raramente estudo teórico (23\%). Isso indica que as teorias estão advindo de estudos que comprovam empiricamente os resultados. No tocante aos instrumentos mais 
utilizados para coleta de dados dessas pesquisas qualitativas foram encontrados métodos como entrevistas com professor e com crianças, gravação de áudio, gravação de vídeo, fotografias, material produzido pelas crianças, observação e o diário de campo. Pode-se perceber que a maioria das pesquisas empíricas envolveram mais de uma ferramenta de coleta de dados para alcançar seu objetivo, apenas os artigos AR1, AR3, AR7, AR13, AR14, AR19, AR24, AR29, AR30, AR32, AR33, AR34, AR36 e a dissertação DI4 utilizaram-se de apenas um instrumento. Isso faz compreender que as pesquisas na educação matemática buscam por uma coleta de dados diversa, principalmente quando se trata de dissertações e teses. Tal fato confirma a pertinência e importância da utilização de vários instrumentos para a coleta de dados, pois dificilmente por meio de somente um recurso se consegue perceber o máximo possível da realidade investigada e sua relação com o tema da pesquisa. "A combinação de diferentes perspectivas metodológicas, diversos materiais empíricos [...] num só estudo devem ser vista como uma estratégia para acrescentar rigor, amplitude, complexidade, riqueza e profundidade em qualquer investigação" (DENZIN; LINCOLN, 2000, p. 36).

Destaca-se que uma das dificuldades encontradas na análise foi identificar a metodologia utilizada na elaboração dos artigos, já que poucos dedicavam um espaço para tratar dela e, em alguns deles, nem mesmo citava-a, fazendo por vezes, apenas pequenas referências na introdução. Isso "não significa que se possa fazer pesquisa sem método. $\mathrm{O}$ trabalho de investigação não pode prescindir de rigor e método, mas você pode inventar seu próprio caminho" (COSTA, 2002, p. 154). No entanto, quando há carência nos procedimentos metodológicos, a confiabilidade da pesquisa pode ficar prejudicada. No tocante à procedimentos de análise, o modo escolhido para fazê-la também não foi algo tão bem expresso. Em TE2 foi utilizada a Triangulação para análise dos dados, sob a perspectiva de Buendía et al. (1999), em AR2 e TE1 com a Análise de Conteúdo de Laurence Bardin e em DI9 que utilizou os procedimentos da Análise Textual Discursiva. Ademais, AR29 destaca como fez a revisão sistemática baseada Cordeiro et al. (2007) enquanto que o AR32 que fez uma pesquisa do estado da arte, sob a perspectiva de Ferreira (2002) e Soares (1989). Já a Engenharia Didática (ALMOULOUD, 2007) foi utilizada em AR20 e nos demais estudos, os autores optam por 'inventar' seu próprio modo de fazer análise a fim de expressar as conclusões, fato já destacado por Costa (2002). Percebeu-se 
que as teses apresentam muito bem clara e definida a parte destinada aos procedimentos de coleta e análise de dados, mas isso não significa que quando os autores não utilizam algum método já bastante difundido o estudo não tenha que confiabilidade, como destaca Costa (2002).

No tocante à fundamentação teórica utilizada nos estudos, ela concentra-se no campo da educação, da educação matemática e da psicologia, percebendo-se uma grande tendência ao sociointeracionismo (19 estudos) e ao construtivismo (15 estudos). Os autores mais frequentes entre os estudos foram: Jean Piaget, Lev Semyonovich Vygotsky, Constance Kamii, Paulo Freire, Gérard Vergnaud, Alexis Nikolaevich Leontiev, Ubiratan D’Ambrósio, Sérgio Lorenzato, Manoel Oriosvaldo de Moura, Kátia Cristina Stocco Smole e colaboradores, Sonia Kramer e Tizuko Morchida Kishimoto. Apesar de se tratar de diferentes teorias ou estudiosos, grande parte dos estudos compila, na sua fundamentação teórica, mais de uma perspectiva, de modo a abranger e comparar diversas teorias pedagógicas e de desenvolvimento. Documentos oficiais como a BNCC (BRASIL, 2018) e as DCNEI (BRASIL, 2010), apesar de não serem teorias, também foram utilizados nas discussões.

Referente às metodologias, recursos ou estratégias de ensino de matemática, o estudo DI6 e AR18 utilizam a Etnomatemática e o DI3 fez uso de Modelagem Matemática como metodologia específica. Além disso, os artigos AR26, AR29 e AR38 trabalham a Resolução de Problema para o ensino da matemática. Outras ferramentas para auxiliar no processo de ensino-aprendizagem foram: a literatura (AR13, AR21, AR26), as tecnologias digitais (AR27), e, o mais citado, o jogo (AR2, AR4, AR6, AR26, AR29, AR30, AR37, AR38, DI1, DI3 e DI7). Portanto, são bem variadas as formas de abordagem utilizadas no processo de ensino de (noções) matemáticas, indicando que recursos ou procedimentos de ensino geralmente utilizados nas etapas seguintes da Educação Básica também podem corroborar no trabalho do professor da EI.

Os conhecimentos prévios foram considerados e destacados em 15 dos estudos, ancorados no fato de que as crianças antes de ingressar na escola já possuem conhecimentos matemáticos, sendo a escola um espaço para revisar, aprofundar e ampliar de modo formal. Afinal, como bem afirmam Smole, Diniz e Cândido (2000), é cotidianamente que as crianças se deparam com situações que envolvem quantidades, números e noções de 
espaço, utilizando recursos próprios para resolver. Para isso, percebeu-se referência à uma abordagem de trabalho docente na perspectiva de um ensino contextualizado ( 8 estudos), significativo ( 7 estudos) e lúdico ( 8 estudos), sendo o jogo a principal ferramenta utilizada para auxiliar no trabalho com as crianças.

Em relação aos principais resultados e contribuições das pesquisas identificou-se que $72 \%$ delas apresentam contribuições relativas ao ensino e aprendizagem de noções matemática, sendo uma pequena parte voltada à alfabetização matemática $(11 \%)$ e outra à docência (17\%). Referente a alfabetização matemática, os estudos (AR3 e AR4) concordam que deve-se pautar pelo ensino contextualizado e significativo, partindo dos conhecimentos prévios da criança, sem se restringir a memorização e repetição, para assim desenvolver a linguagem como uma prática social, reflexiva e transformadora. Os estudos que tratam das práticas de ensino-aprendizagem seguem o mesmo princípio pedagógico, além de considerar o desenvolvimento global dos estudantes, buscando desenvolver a autonomia e a criatividade. Outros estudos também destacam que a aprendizagem não se dá de forma linear, mas sim por meio de situações lúdicas e emergentes, enfatizando a problematização e resolução de problema como estratégia pedagógica para o ensino de noções matemáticas. No tocante à docência, nove delas (AR12, AR17, AR19, AR20, AR25, DI5, DI9, TE1 e TE2) tiveram foco e trouxeram contribuições para formação e atuação docente. Em 16 estudos (AR3, AR4, AR6, AR10, AR12, AR17, AR20, AR23, AR27, AR29, DI5, DI4, DI7, DI8, DI9 e TE1) tem-se indicativos de que a formação inicial e continuada do professor é a principal lacuna entre os estudos de educação matemática da EI, reconhecendo ser essencial para prática docente a reflexão durante o processo educativo.

As pesquisas apontam para uma tendência pedagógica mais próxima da pedagogia progressista (LIBÂNEO, 1992) ao passo que em várias realidades escolares ainda se há predomínio de uma pedagogia liberal, fato emergente nos estudos empíricos desenvolvidos. Desse modo, pode haver um vácuo entre o conhecimento científico e as práticas pedagógicas e, no entanto, enquanto os dois buscam os mesmos objetivos, cada um pode estar permanecendo obstinado em seu próprio espaço. O que estaria ocorrendo para que os resultados das pesquisas científicas ainda permaneçam sutilmente presentes realidade escolar e dos centros de EI? Por que esses lugares tendem a percebem os 
resultados das pesquisas como oportunidade para de julgar e contrapor com seus fundamentos teóricos ao invés de contribuição para o desenvolvimento?

$\mathrm{O}$ mais próximo que as pesquisas científicas permanecem da realidade escolar e dos centros de EI é para julgar e contrapor com seus fundamentos teóricos, e as escolas em abrir seu espaço e se afastar o mais breve possível. Daí resulta uma grande lacuna, a produção de conhecimento 'da' e 'para' a escola, socializados com a comunidade escolar e visando atender os interesses e necessidades das crianças e professores. Além disso, os resultados desses estudos, indicam a necessidade de ainda mais pesquisas sobre o tema relacionado principalmente à formação da(o) pedagoga(o) como professor polivalente, bem como sua formação continuada.

\section{CONSIDERAÇÕES FINAIS}

O estudo buscou compreender o que versam os estudos brasileiros que tratam do ensino-aprendizagem de (noções) matemática(s) na Educação Infantil, considerando os processos pedagógicos e o desenvolvimento da criança. A partir da realização da pesquisa podemos perceber que diversos estudos abordam o ensino-aprendizagem de (noções) matemática(s) na Educação Infantil e todos eles, identificados na revisão realizada, apontam para uma concepção pedagógica promotora da autonomia, da reflexão, da criticidade e da criatividade, compreendendo a criança como sujeito histórico, produtor do conhecimento e ativo no processo de ensino-aprendizagem. Eles indicam que a aprendizagem das noções matemáticas se dá por diferentes estratégias, recursos ou métodos de ensino, porém, destaca-se a importância do lúdico e da problematização de situações emergentes, proporcionando uma aprendizagem significativa e contextualizada.

Percebeu-se que vários dos estudos vêm contribuir com o tema - o ensinoaprendizagem de (noções) matemática(s) na EI-, destacando que trata-se de processo intrínseco a vida da criança devendo a educação formal, para isto, considerar seu contexto, seus conhecimentos prévios, seus interesses e suas necessidades para construir o conhecimento matemático por meio de uma aprendizagem lúdica e significativa. A aquisição do conhecimento matemático na infância é singular, possui suas particularidades a serem consideradas no processo de ensino-aprendizagem, considerando-as como um sujeito ativo e centro da aprendizagem, cabendo ao professor mediar o processo a partir 
desses princípios. Apesar de pesquisas anteriores como a de Sanchez Junior, Blanco e Coelho Neto (2017) evidenciarem a excessiva concentração dos estudos nos professores, se constatou no decorrer dessa pesquisa que os estudos estão buscando compreender o processo de ensino aprendizagem para além dos docentes, porém ainda faltam pesquisas focadas no processo de aprendizagem da matemática nessa etapa escolar. Por fim, a formação do docente polivalente é bastante discutida quando se refere às áreas do conhecimento específico, necessitando ainda mais pesquisas referentes principalmente à formação inicial e continuada da(o) pedagoga(o), relacionadas à matemática.

Para a educação essas constatações são de destacada importância servindo como direcionamento para futuras pesquisas da área, assim como possibilitam compreender o que os estudos já produzidos respondem e indicam para a educação matemática brasileira. Em relação as perspectivas de continuidade, esse estudo pode ainda se estender buscando compreender a prática docente e o processo de ensino-aprendizagem de matemática a partir de dados empíricos, e/ou ainda preencher a lacuna quanto a formação (inicial) docente do professor da Educação Infantil.

\section{REFERÊNCIAS}

ALMOULOUD, S. A. Fundamentos da didática da matemática. Curitiba: Ed. UFPR, 2007.

BARBOSA, C. P.; FERREIRA, A. C. Psicologia e educação matemática: um olhar sobre as pesquisas produzidas no Brasil. In: Encontro Nacional de Educação Matemática ENEM, 9, 2007, Belo Horizonte. Anais [...]. Belo Horizonte: SBEM, 2007. p. 2-18.

BIEMBENGUT, M. S. Mapeamento na pesquisa educacional. 1. ed. Rio de Janeiro: Ciência Moderna, 2008.

BUENDÍA, L. Modelos de análisis de la investigación educativa. Sevilla: Alfar,1999.

BOGDAN, R. C.; BIKLEN, S. K. Investigação qualitativa em educação: uma introdução à teoria e aos métodos. Lisboa: Porto Editora, 1994.

BRASIL. Diretrizes Curriculares Nacionais Gerais da Educação Básica. Brasília: MEC, 2013. $562 \mathrm{p}$.

. Ministério da Educação e do Desporto. Base Nacional Comum Curricular. Brasília: MEC/SEF, 2018.

Diretrizes Curriculares Nacionais para a Educação Infantil. Brasília: $\overline{\mathrm{MEC} / \mathrm{SEB}} 2010$.

CAVALCANTE, C. O. A orientação espacial na pré-escola: analisando saberes docentes. 2015. 125 p. Dissertação (Mestre em Educação) - Universidade Federal do 
Ceará, Fortaleza, 2015.

CNPQ. Conselho Nacional de Desenvolvimento Científico e Tecnológico. Censo atual. [S. 1.], 2016. Disponível em: <http://lattes.cnpq.br/web/dgp/censo-atual/> . Acesso em: 13 out. 2019.

CORDEIRO, A. M. et al. Revisão sistemática: uma revisão narrativa. Revista do Colégio Brasileiro de Cirurgiões, v. 34, n. 6, p. 428-31, 2007. Disponível em: $<$ https://doi.org/10.1590/S0100-69912007000600012>. Acesso em: 30 jun. 2020.

COSTA, Marisa Vorraber et al. Caminhos Investigativos: Novos Olhares na Pesquisa em Educação. 2. ed. Rio de Janeiro: DP\&A, 2002.

DANYLUK, O. S. Alfabetização Matemática: o cotidiano da vida escolar. Passo Fundo: Gráfica e Editora UPF, 1989. 126 p.

. Alfabetização matemática: as primeiras manifestações da escrita infantil. 5. ed. Passo Fundo: Universidade de Passo Fundo, 2015. 248 p.

DENZIN, N. K.; LINCOLN, Y. S. The discipline and practice of qualitative research, In: DENZIN, N. K.; LINCOLN, Y. S. Handbook of Qualitative Research. Thousand Oaks: Sage, 2000. p. 1-36.

FERRAZ, A. P. C. M.; BELHOT, R. V. Taxonomia de Bloom: revisão teórica e apresentação das adequações do instrumento para definição de objetivos instrucionais. Gestão \& Produção, São Carlos, v. 17, n. 2, p. 421-431, 2010.

FERREIRA, N. As pesquisas denominadas "Estado da Arte". Educação e Sociedade, ano 23, n. 79, ago. 2002.

GIL, A. C. Como elaborar projetos de pesquisa. 4. ed. São Paulo: Atlas, 2009.

KAMII, C. A criança e número: Implicações da teoria de Piaget para a atuação com escolares de 4 a 6 anos. Campinas: Papirus, 2012. 112 p.

KRAMER, S. A política da pré-escola no Brasil. São Paulo: Cortez, 1992.

. As crianças de 0 a 6 anos nas políticas educacionais no Brasil: Educação Infantil e/é fundamental. Educação \& Sociedade, Campinas, v. 27, n. 96, p. 797-818, out. 2006.

LIBÂNEO, José Carlos. Tendências pedagógicas na prática escolar. In:

Democratização da Escola Pública - a pedagogia crítico-social dos conteúdos. São Paulo: Loyola, 1992. cap 1.

LORENZATO, S. Educação Infantil e percepção matemática. 3. ed. rev. Campinas: Autores Associados, 2011. 201 p.

MORETTI, V.; SOUZA, N. M. M. Educação Matemática nos Anos Iniciais do Ensino Fundamental: Princípios e Práticas Pedagógicas. 1. ed. São Paulo: Cortez, 2015. 216 p.

SANCHEZ JUNIOR, S. L.; BLANCO, M. B.; COELHO NETO, J. Uma revisão sistemática sobre o ensino da matemática na Educação Infantil. Revista de Educação, Ciências e Matemática, Duque de Caxias, v. 7, n. 3, p. 24-36, set. 2017.

SILVA, P. F. Modelagem Matemática na Educação Infantil: uma estratégia de ensino com crianças da faixa etária de 4 a 5 anos. 2013. 172 p. Dissertação (Mestrado), 
Universidade do Vale do Taquari - Univates, Lajeado, 2013.

SMOLE, K. S.; DINIZ, M. I.; CÂNDIDO, P. (org.). Brincadeiras Infantis nas aulas de matemática. Porto Alegre: Artmed, 2000. 92 p.

SOARES, M. Alfabetização no Brasil - O estado do conhecimento. Brasília:

INEP/INEP/MEC, 1989.

WEISZFLOG, W. Michaelis: Dicionário Brasileiro da Língua Portuguesa. São Paulo: Melhoramentos. Disponível em:

$<\mathrm{http}: / /$ michaelis.uol.com.br/moderno/portugues/index.php>. Acesso em: 10 maio 2019.

Submetido em 06 de julho de 2020. Aprovado em 30 de novembro de 2020. 